\title{
USING HOSPITAL ARCHIVAL DATA TO RESEARCH THE HISTORY OF NURSING: KING GEORGE V JUBILEE HOSPITAL - AN EXAMPLE
}

\author{
Y.G. Pillay
}

\section{INTRODUCTION}

The history of a medical institution and those who have worked in it can provide valuable insights into the nature of the health care of a particular historical period. While it is acknowledged that health care is provided both inside and outside medical institutions, the hospital has significantly shaped the nature of health care in general and the role of nurses in particular since the turn of this century (Reverby 1985).

The use of hospital records to amplify medical history is well documented (Goubert 1987). Verious types of important data such as numbers of births, deaths, admission rates for various types of diseases, types of diseases, treatment regimens, lengths of hospital stay and the roles played by the various health practitioners have been gleaned from these sources.

While descriptive studies of hospitals are useful - and hospital records are usually an appropriate and rich source of such descriptions - they have several limitations. Risse $(1987,175)$ argues that descriptive studies "...fail to probe the actual nature and operations of institutional confinement... Moreover, the meaning, status and economic benefits provided for medical professionals by the hospital affiliation are seldom explored".

This paper concentrates on the history of King George V Hospital in Durban and will attempt to illustrate both the concerns and some of the 'silences' both on the part of those who administered the hospital and those of printed media such as newspapers. Various categories of health practitioners were employed by the King George V Jubilee Hospital but by far the most numerous and important, with respect to the care of what was then a chronic condition (tuberculosis), was the nursing staff. Given their importance, this paper will focus on the hospital and the nursing profession over the period 1939-1948 which were the first ten years of the hospital's existence.

\section{DATA SOURCES AND METHODOLOGY}

As already stated data kept in the hospital archives and made available to the researcher by the current chief medical superintendent were used in developing this paper. The data included copies of the annual reports submitted to the Minister of Public Health, and pertinent newspaper articles which had been compiled by one of the medical staff employed by the hospital. These latter were largely articles either about the hospital or tuberculosis which were published in the Natal Mercury, Natal Daily News and the Guardian. The constraint of this limited data source is acknowledged, but it is argued that these sources, while providing a biased sample, may be used to represent at least the point of view of those in power and therefore in influential positions at that time.

In terms of the methodology used this paper employs the historical method using both published and unpublished primary data that may be in the form of words, numbers, images or objects (Fee and Fox, 1988). Historians are aware of the possible dangers in the process of reconstruction. The possibility of both distortions and presentism are emphasised. Presentism refers to "...judging the values of yesterday or the day before yesterday with the yardstick of the values of our time" (Goubert 1987, 43).

Risse (1987) suggests that it is inadequate to describe merely the history of a hospital and even less adequate to portray the achievements of a hospital as the result of efforts of individuals. He argues that it is necessary to combine various perspectives, including that of the administration of the hospital, the people who worked in it and the consumers of the care, in order to obtain a comprehensive picture of the hospital which will transcend stereotypes.

The records made available to the author by the chief medical superintendent of the hospital contained data reporting on the physical state of the hospital (including adequacy of storage facilities and accommodation for nurses), the number of staff employed and the number of staff in the various categories, and patient characteristics such as race, diagnosis, mortality, procedures carried out and length of patient stay. Other data, for example, reports by nurses on their perceptions of their work and work environment (with the exception of the letter to the editor that is quoted in full below) and that of the patients were not available to the author. Their importance is however acknowledged.

\section{THE CONTEXT OF WORK - KING GEORGE V HOSPITAL, THE 'BROMPTON OF SOUTH AFRICA'}

While the hospital was officially opened on the 31 March 1939 it had admitted its first patient on 6 January of that year. A newspaper (name and date unknown) commenting on the new hospital stated that "the building, which looks more like a luxurious hotel than a hospital, provides nurses with the most modern labour saving devices...". The hospital was dubbed the "Brompton of South Africa' as the aim was to make it as prestigious as London's Brompton Hospital for diseases of the chest.

The siting of the hospital in Durban proved to be controversial. Non-professional opinion at the time was that tuberculotic patients required a dry climate; it was believed that tuberculosis was chiefly a disease found in people living in humid coastal areas and that therefore the climate of Durban was unsuitable for the treatment of such patients. Such was the strength of this opinion that in opening the hospital, Dr. E. Cluver, the Secretary of Public Health addressed the issue and went on to point out the benefits of locating the hospital in Durban (The Natal Mercury, 1 April, 1939). The matter also was referred to in a letter to the editor of The Natal Daily News written by a member of the King George $V$ nursing staff which will be quoted fully later.

The hospital was administered during this period by Dr. B.A. Dormer who was both an administrator and a medical scientist. $\mathrm{He}$, together with a collaborator, developed the first portable X-ray machine to be used in the field. He was also one of the first medical 
practitioners to relinquish the notion that blacks were more susceptible to the disease than whites. Packard (1989) described him as an 'environmentalist' given his appreciation that poor nutrition, overcrowding and poverty were contributory to the tuberculosis epidemic. While Dr. Dormer appeared to be a visionary in some respects he administered a hospital that practised racial discrimination which supports Packard's view that the response of Dormer and other environmentalists to the tuberculosis epidemic was classically medical rather than social.

That patient segregation along racial lines predated the election of the first National Party government in 1948 is illustrated by the fact that in planning the hospital provision was made for four separate wards, one for each race group. The number of beds allocated to each of the race groups in the original plan was as follows:- 35 for whites; 63 for blacks; 21 for Indians; and 20 for coloureds but black patients, in fact, were not admitted until 1946. Until 1946 black tubercolotic patients were treated at King Edward VIII and the Point Non-European Hospitals which were both general hospitals.

For the first six years of its existence the King George had a bed state of 76 'White beds' and 73 'Coloured and Indian beds'. This allocation of beds should be viewed in the context of the tuberculosis infection rates of that period. In the annual report of Dr Dormer. the medical superintendent of the hospital dated 30 June 1939, the following population figures and numbers of active tuberculosis cases in Natal were documented. Of 190551 whites there were 60 known cases of uberculosis; of 18,513 coloureds there were 63 active cases; of of 183, 646 Indians there were 27 cases; and of 1,533,930 blacks there were 2895 active cases. These figures clearly suggest that the priority in the allocation of beds was racial and not need motivated.

The segregation of patients by race was hospital policy which was apparently acceptable to the health practitioners. That the nabure of the disease was not a rationale for the social separation of the races is supported by the understanding by the medical profession of the causes of tuberculosis.

The chief cause of the disease, according to a resolution adopted at a conference hosted by the Department of Public Health held in January 1939, was "...to be found in the depressed social and economic conditions of large sections of the population resulting in undernourishment, overcrowding and other factors promoting tuberculosis" (The Guardian, 10 February, 1939). The newspaper added that the health authorities also condemned the "...policy of segregation, of low wages, of keeping prices high because our own people are too poor to form a sufficient market...". This admission did not, however, translate to the denouncement of hospital segregation.
THE NURSING ST AFF AND SOME OF THEIR CONDITIONS OF WORK

From the first year of its operation the hospital appeared to experience difficulty in attracting and keeping nursing staff. This is reflected in the first annual report of the medical superintendent, Dr. Dormer. In this report he speculated about the possible reasons for this:

\section{General lack of trained nurses.}

2. Objections by nurses to serving at a tuberculosis hospital

3. Distance of the hospital from the centre of town and the lack of adequate transport facilities.

\section{The area in which the hospital was} situated in the middle of Indian slums and the persistent rumour that women are attacked in this neighbourhood, especially at night" (Dormer 1939, 7).

Dormer did not speculate about the reasons for the general lack of nurses and nor did he specifically mention whether there was a shortage of nurses in all race groups. Critical Health (1988) suggests that Afrikaans women were reluctant to enter the profession because of the nature of the work ie. largely domestic in nature, the long hours, the poor living conditions in hospital nurses' quarters and the attitude of senior English-speaking nurses to them. While nursing as a profession has always been prestigious in African communities, Critical Health (1988) suggests that by 1948 there were only 800 trained African nurses nationally. The small numbers of African nurses is attributed to the poor level of primary and secondary level education that they received and the reluctance of many hospitals to provide training facilities.

For King George V Hospital there were three specific consequences of this shortage of trained nurses: (a) one empty ward (of 40 beds) at a time when there was a waiting list of some 40 patients seeking admission to the hospital; (b) the delay in the commencement of major thoracic surgery; and (c) the increased workload on the existing nursing staff. With regard to the latter, a report on surgical therapy dated 1939/40 bemoaned the lack of a theatre sister: "There is still a need for a theatre sister, as a surgeon and team cannot be expected to do efficient thoracic surgery unless a permanent theatre sister is part of the unit".

The importance of the nursing profession to the health profession and for adequate patient care was thus emphasised by the severe shortage of trained nurses.

With the shortage of staff already critical the hospital authorities were concemed that staff not be infected. To ensure their health, all staff were X-rayed once a year. The annual report of 1939 also raised the issue of the hospital's liability in the event of a member of staff contracting tuberculosis whilst on duty and asked the Department of Public Health for a ruling on the issue of hospital liability. There is no record, in the data available, of a response to this issue.

Concern for the health of the nursing staff was again indicated by the complaint of the medical superintendent in the second annual report (1940) to the Department of Public Health. In this report the inadequacy of the accommodation available to the nurses was raised. The nurses' home was described as being "...damp and unhygienic" (Dormer 1940:3). The report suggestod that these conditions were contributory to the significant increase in asthma and bronchitis among the nurses and states that "It is wrong to allow young girls to live in damp and unhygienic surroundings ... and then expect them to nurse tuberculosis patients" (ibid). The report also indicated that numerous requests to the Public Works Department to have the Nurses' home damp-proofed had been unsuccessful. While the report does not mention whether it was referring to the white or black nursing residence, given the report of the Natal Mercury (below), it appears reasonable to conclude that the report was referring to the former. The Natal Mercury of 30 March 1939 described the nurses' accomodation at the hospital as follows: 'The nurses' quarters have been built on the lines of a modern hotel, and each room is designed to serve as a sitting room as well... there are silver tea sets provided, stamped with the Union badge - a lion". The article failed to report on the type of accommodation for black nurses. They were housed in compounds, with each room being shared by four occupants. Shower facilities were to be found in the court yard.

The inadequacies in the sccommodation of some of the nursing staff was again documented in the annual report of the following year (1941). Beside the unhealthy conditions referred to previously the report cited the need for alternative accommodation for the night staff "...as their present quarters are in the centre of the hospital's activities and they never get any sleep". This report also documented the fluctuation in the number of nursing staff and the inclusion of tuberculin testing in the screening procedure used to ensure the health of staff.

The annual report of 1942 began with a paragraph on the nursing shortage and the consequent increased workload for the staff. This was contrasted with the working conditions of the nurses employed in the neighbouring Springfield Military Hospital:

"There are very few women who would carry on cheerfulty with extra work in a tuberculosis institution when nex door at the local military establishment the nursing staff is fully complete in numbers and surrounded by glamour" (Dormer 1942,I).

The annual report of 1941 also gave an indication of how the hospital responded to the 
shortage of nurses. Temporary nurses were employed to make up the shortage of permanent staff. The reasons for these temporary nurses not being employed on a permanent basis is unclear from the report but they may have been nurses who returned to work on a part time basis after retiring.

The report documents the medical superintendent's gratitude to the permanent nursing staff who, while being paid a lower salary than the temporary staff also had to carry all the responsibility as the latter were unwilling to assume responsibility. It is possible that the temporary staff were paid more as an incentive to work at the hospital given the reluctance of nurses to being employed at a tuberculosis hospital.

The commitment of the nursing staff, despite the working conditions can be said to be represented by the letter, written by a nurse employed at King George, to the editor of the Natal Daily News, March 31, 1942. This letter was written in response to a letter to the editor of the same paper which criticised the proposal to raise 5,000 pounds for the construction of a recreation hall at the Springfield Sanatorium. The correspondent believed that this was a waste of money as he/she did not think that the climate of Durban was conducive for the treatment of tuberculosis; the dry climate of the Karoo was considered superior. In response the nurse wrote:

"At the moment I am nursing a TB. patient who is in the happy position of being able to pay for treament in any part of the world. He became worse in the Cape, developed complications and completely collapsed in the Karoo, and in despair tried Springfield. There he cheated death during December, is now an out-patient... and is expected to be leading a normal life in another six months. Anong many rules governing the cure of TB. is one of psychology, that a patient' s mind mus be kept happy and interested as an offset to the sympioms of depression, nervous worry and a tendency to self-pity. Remembering this, one can understand that a recreation hall is an essential feature of life in this sanatorium...".

The above quotation does not only suggest the attitude of the nurse to the institution but also the level of understanding of the psychological needs of the patient in a long term institution. This type of understanding suggests that the health care providers of this period were concerned about the entire human being and not only the presence or absence of the disease.

The shortage of nurses continued to be the major problem of the hospital in 1943. Dr. Dormer was quoted in the Natal Daily News of October 21, 1943 as stating that the hospital was functioning with only 6 trained and 14 untrained nursing staff to provide care for 128 patients. The required complement of nursing staff was 50 . He was also reported as stating that there was a prejudice against working in a tuberculosis hospital because of the fear of infection. He argued that this possibility was almost nil citing the fact that in the history of the hospital none of the staff had contracted the disease.

By 1943 the nursing shortage appeared to be a national problem. The Cape Argus, 16 February, 1943 reported that 100 beds were empty, despite a long waiting list, in the Cape Peninsula. A similar number of beds were also empty in Johannesburg for the same reason. A fully equipped hospital in Springbok was empty as a result of the shortage of nursing staff. At the King George there was a waiting list of $\mathbf{4 0}$ patients due to nursing staff shortages.

The South African Nursing Journal of April 1943 , in response to the national shortage of nurses, suggested that this was an international problem largely a result of the war which resulted in the call-uip of nurses for military service. However the journal agreed that the shortage was not uniform: "In South Africa, as in England, the shortage is most acute as regards the Tuberculosis Hospitals; the Union Secretary for Public Health has made an urgent appeal for our help in providing trained staff for the King George V Hospital in Durban. It will be remembered that this hospital is quite the most advanced hospital in the Union in the variety and range of treatments undertaken, so that the work is stimulating and interesting. It is suggested that if nurses who have retired from private practice during the recent months or years or nurses in private practice would undertake service in that or other Tuberculosis Hospitals in sufficient numbers, the hours could be adjusted to their possibly lowered physical capacity; and they would be rendering a truly National Service in time of National Emergency".

Dr. Dormer was reported by the Natal Daily News (ibid) as suggesting the need for the Department of Public Health to replicate the experience of the British and advertise for nursing staff widely. In South Africa posts were only advertised in the Government Gazette which Dormer argued had a limited readership. He also suggested that the requirement that nurses live in nurses' quarters in the hospital grounds was a deterrent as young women did not enjoy living under the watchful eye of the matron as they were responsible adults and not children. The impression created by these suggestions is that nurses of this period were treated as irresponsible children who had to be looked after. It is likely that this type of supervision was achieved by very rigid authority structures and with a large number of rules to which they were expected to conform.

The hospital employed both white and black nurses of all categories ie. sisters, staff nurses, and nursing assistants. However, only whites were appointed as matrons. The annual reports reviewed did not indicate the numbers of the various categories of black staff employed during this period. An undated and unsigned report entitled 'Nursing Staff' proposed the following salary scales of the various categories of nursing staff:

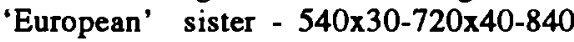
(pounds); 'native' sister - 290×20-350 (pounds); 'European' female - nursing assistant was $300 \times 30-540$; and 'native' nursing assistant - $132 \times 12-180-198$. While it is recognised that these were proposed salary scales it seems reasonable to suggest that the salary structure that was used at the time was also discriminatory. Measures (primarily dismissal) were also instituted to curb what was considered to be a high absenteeism among the 'native' staff due to large numbers of pregnancies.

There were instances of apparent nursing staff dissatisfaction at King George which were reported in the official annual reports. The first was in 1946 when black male nurses, who became part of 'the nursing staff of the hospital through the incorporation of the Springfield Military Hospital, had their letters of resignation accepted. These letters had been tendered as a form of protest in order to secure better working conditions - the specific conditions that were being protested were not documented. Such protest action undertaken by the nurses apparently suited the hospital authorities and the medical superintendent suggested in the annual report of 1946 that the male nurses did not fit into the future nursing plans of the hospital.

The second instance in which nursing staff were dismissed was in 1948 when 48 student nurse aides were expelled after embarking on strike action. The reasons for their action were not recorded in the annual report of the hospital. In order to prevent a recurrence, the hospital authorities formulated a contract which all new students were expected to sign before acceptance into the course. Details of the new contract were not recorded in the report of 1948 .

\section{SOME OF THE 'SILENCES'}

While some of the 'silences' have been alluded to in the sections above, it may be useful to recap and elaborate on them. An important silence concerns the nature of the treatment received by patients of the various race groups and staff attitudes to patient ratios in the various sections of the hospital ie. the difference between the white and black wards. The per capita amount spent on patients of different race groups is known - 250 pounds per white patient as opposed to 120 pounds per black patient (The Natal Mercury, 6 May, 1944). The precise way in which this difference translated into the delivery of care is not known. For instance, what proportion is contributed by the large difference in nurses' salaries or nurse:patient ratio is unclear.

The nature of the working conditions of the nurses are only hinted at in the documents that were reviewed. Details of the day-to-day activities of the nurses, the differential 
treatment of nurses of different race groups by the nursing administration and hospital administration (apart from salary and accommodation), the precise reasons for the two strikes, the nature of the contract that all student nurse aides were expected to sign, the social life of the nurses and the nature of the relationship between black and white nurses were not available.

While both the medical profession and the hospital administration appeared to realise the negative implications of racial discrimination on health status this seemed not to impact on the way in which the hospital was administered or on the way in which the nursing staff was treated. Black nurses were discriminated against as reflected in both their salary structures and the accommodation provided by the hospital. This can be argued to be an example of a 'silence' as there is no record of the hospital administration protesting against racial discrimination as it pertained to the delivery of health care to the Department of Public Health.

It is acknowledged that these 'silences' may have been articulated and either not documented or documented in material not reviewed by the author. While a more extensive review of data of this period may unearth more of the details (and this is considered necessary) the use of hospital records is illustrative of the perceptions of the hospital administrators of the time. Their perceptions are important because they are major players in constructing (or obstructing) the development of new health policy. This suggestion is supported by De Beer (1984) who provides evidence to suggest that the Gluckman proposals of 1948 which proposed the creation of a non-racial National Health Service were not implemented partly because of opposition by the medical profession.

\section{CONCLUSION}

While the use of hospital archival data can be argued to be 'incomplete', this paper suggests that an important perspective such as that of the hospital administration and the medical profession is represented by it. As such an exploration of this data can contribute to the understanding of the history of a particular institution and/or profession.

The first ten years of the history of the King George V Jubilee Hospital were marked by the ambition of the hospital to become the pre-eminent tuberculosis hospital in the Union. However, it would appear that while it did become a leading hospital for the care of the tuberculotic, it had to contend with critical shortages of nursing staff which led to ward closures, waiting lists for admission and a reduction in the number of surgical procedures that could be performed.
The patients and nursing staff were segregated by race and appeared to have had differential access to resources as a consequence. While there is evidence to suggest that the hospital authorities and the Department of Public Health appeared to acknowledge the negative health implications of the policy of racial discrimination, there seems to be no evidence to suggest that the hospital authorities sought to equalise the treatment of either patients or nursing staff.

Another feature of the period under review was the critical shortage of nurses. While it is acknowledged that this was partly a consequence of the war, the fact that the tuberculosis nospitals, notably King George $V$, were more drastically affected than the general hospitals suggests that other reasons were contributory. The poor working conditions and the fear of infection were some of the important reasons for the shortage of nurses.

The importance of the nursing profession in general and in the care of patients with chronic and infectious diseases in particular was emphasised by the history of the period under review. The nursing staff was viewed as a crucial component of the health care team in the treatment of tuberculosis and the shortage resulted in fewer surgical procedures and, perhaps more importantly, fewer admisions at the height of the epidemic. The importance of this historical experience should not escape a society which is currently confronted with the AIDS pandemic and the increase in the incidence of other chronic diseases where care and not cure is more appropriate.

\section{REFERENCES}

CRITICAL HEALTH (1988). The Origins of Contemporary Nursing Organisation in South Africa. No. 24, 4-12. October.

DE BEER, C. (1984). The South African Disease: Apartheid Health and Health Services. Johannesburg: Southern African Research Service.

DORMER, B.A. (1939). Annual Report for the year ending 30 June 1940 . Unpublished report to the Department of Public Health, Union of South Africa.

DORMER, B.A. (1941). Annual Report for the year ending 30 June 1941. Unpublished report to the Department of Public Health, Union of South Africa.

DORMER, B.A. (1942). Annual Report for the year ending June 1941. Unpublished report to the Department of Public Health, Union of South Africa.
FEE, E. AND FOX, D.M. (1988). Aids: The Burden of History. Berkeley: University of Califormia.

GOUBERT, J.P. (1987). Twenty Years on: Problems of Historical Methodology in the History of Health. In R. Porter and A. Wear (eds) Problems and Methods in the History of Medicine. London: Croom Helm.

PACKARD, R.M. (1989). White Plague, Black Labour: Tuberculosis and the Political Economy of Health and Disease in South Africa. Berkeley: University of California Press.

REVERBY, S. (1985). The Search for the Hospital Yardstick: Nursing and the Rationalization of Hospital Work In J.W. Leavitt \& R.L. Numbers (eds). Sickness and Health in America: Readings in the History of Medicine and Public Health. Madison: University of Wisconsin Press.

RISSE, G.B. (1987). Hospital History: New Sources and Methods. In R. Porter and A. Wear (eds) Problems and Methods in the History of Medicine. London: Croom Helm.

The Cape Argus, 16 February 1943.

The Guardian, 10 February 1939.

The Natal Daily News, 31 March 1942.

The Natal Daily News, 21 October 1943.

The Natal Mercury, 1939.

The Natal Mercury, 30 March 1939.

The Natal Mercury, 1 April 1939.

South African Nursing Journal, April 1943.

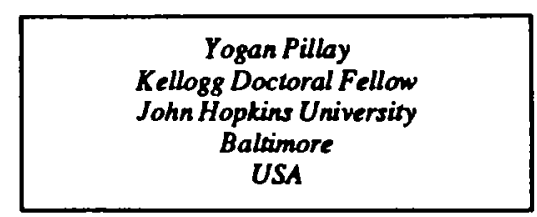

